\title{
Adsorptive removal of C.I. Direct Yellow 142 from textile baths using nanosized silica-titanium oxide ${ }^{\star}$
}

\author{
Monika Wawrzkiewicz ${ }^{1}$, Ewelina Polska-Adach ${ }^{1}$, Małgorzata Wiśniewska $^{2, a}$, Gracja Fijałkowska ${ }^{2}$, and \\ Olena Goncharuk ${ }^{3}$ \\ 1 Maria Curie Sklodowska University, Faculty of Chemistry, Department of Inorganic Chemistry, M. Curie-Sklodowska Sq. 2, \\ 20-031 Lublin, Poland \\ 2 Maria Curie-Sklodowska University, Faculty of Chemistry, Department of Radiochemistry and Colloid Chemistry, \\ M. Curie-Sklodowska Sq. 3, 20-031 Lublin, Poland \\ 3 National Academy of Science of Ukraine, O. O. Chuiko Institute of Surface Chemistry, 17 General Naumov Str., 03164 Kiev, \\ Ukraine
}

Received: 18 April 2018 / Revised: 20 December 2018

Published online: 18 March 2019

(C) The Author(s) 2019. This article is published with open access at Springerlink.com

\begin{abstract}
The adsorption properties of the silica-titanium mixed oxide consisting of $80 \mathrm{wt} . \% \mathrm{SiO}_{2}$ and 20 wt.\% $\mathrm{TiO}_{2}$ (ST20) in relation to C.I. Direct Yellow 142 (DY142) were examined. The experimental adsorption capacity of ST20 for DY142 determined at room temperature equals $104.8 \mathrm{mg} / \mathrm{g}$. The equilibrium data were fitted by means of the Freundlich, Langmuir and Tempkin isotherm models. The values of determination coefficients $\left(r^{2}\right)$ confirmed applicability of the Langmuir $\left(r^{2}=0.990\right)$ isotherm model, the monolayer capacity was found to be $106.5 \mathrm{mg} / \mathrm{g}$. The kinetic parameters calculated from the pseudofirst-order (PFO) and pseudo-second-order (PSO) equations as well as the intraparticle diffusion (IPD) model revealed that the chemisorption is the rate limiting step as the $r^{2}$ value obtained for the pseudosecond-order model equals 0.999 . The PSO adsorption rate constant was found to be $0.070 \mathrm{~g} / \mathrm{mg}$ min. The presence of additives such as electrolytes $\left(\mathrm{Na}_{2} \mathrm{SO}_{4}\right.$ and $\left.\mathrm{Na}_{2} \mathrm{CO}_{3}\right)$ and surface active agents (anionic SDS, cationic CTAB and non-ionic Triton X-100) reduce dye retention compared to systems that do not contain these additives. The presence of the dye with the anionic character in the colloidal suspension of ST20 oxide particles results in considerable increase of the solid surface charge density. In the systems of mixed adsorbates (dye-surfactant and dye-salt) the specific changes in surface properties were obtained - the cationic surfactant has the greatest effect on the solid surface groups type and its concentration.
\end{abstract}

\section{Introduction}

Direct dyes are usually sodium salts of sulphonic acid containing two or more azo groups as the main chromophore. More than $75 \%$ of all direct dyes are disazo or polyazo types. Apart from these, there exist only a few phthalocyanine, azine and non-azo metal-complex dyes of certain importance. In recent years benzidine derivatives have been a very popular group of direct dyes. These dyes originated from production, because benzidine, the traces of which may remain in the final product, exhibits carcinogenic properties (it causes bladder tumours) [1].

Direct dyes are soluble in water and almost completely dissociated in dyeing baths creating coloured anions and sodium cations. The planar structure and high molecular mass of direct dyes cause their tendency to form associated ions (colloidal electrolytes). The degree of their association decreases with the temperature increase as well as in the presence of sodium carbonate and sulphate. Therefore direct dyeing is usually performed at almost the boiling point and under neutral or slight alkaline conditions. Direct dyes are used for cotton, paper, leather, wool, silk and nylon dyeing. They are also used as biological stains and $p \mathrm{H}$ indicators.

Jin et al. [2] reported that 280000 tons/year of various dyes on the global scale are released into wastewaters due to inefficiencies of the industrial dyeing operations. About $30 \%$ of direct dyes in the non-fixed form can be detected in the textile effluents [3]. Direct dyes containing azo groups are subjected to degradation to toxic aromatic amines under anaerobic conditions. In addition, some dyes containing heavy metal ions, such as copper, nickel, chromium or cobalt

\footnotetext{
* Focus Point on "Nanotechnology, Nanomaterials and Interfaces" edited by O. Fesenko, L. Yatsenko.

a e-mail: wisniewska@hektor.umcs.lublin.pl (corresponding author)
} 
have carcinogenic and mutagenic properties [4]. Therefore posing a serious threat to flora, fauna and human health and they must be effectively removed. The literature data report the typical based on adsorption processes wastewater treatment methods characterized by high dye removal efficiency. So far the most frequently applied sorbents were activated carbons, ion exchangers and biosorbents of different types [5]. Currently the researchers' attempts have been focused on finding new, cheap and selective adsorptive materials of significant sorption capacities. The use of the nanosized mixed oxides in the field of environmental protection increases year by year due to their unique physicochemical characteristics. Applicability of the above mentioned adsorbents was successfully confirmed in the hazardous dyes removal from the model aqueous solutions, dyeing baths and textile wastewaters by Rasalingam et al. [6], Wawrzkiewicz et al. [7,8], Pal et al. [9], Ciesielczyk et al. [10] and Tanzifi et al. [11].

The aim of the paper was to evaluate the efficiency of the nanosized silica-titanium oxide in the removal process of the C.I. Direct Yellow 142 dye from aqueous solutions based on the calculated kinetic and equilibrium sorption parameters as well as solid surface charge density results. Adsorption properties of the materials based only on silica and alumina are well understood and broadly investigated. There are few reports in the literature regarding the use of mixed oxides as adsorbents. Their practical application is described mainly in photocatalytic degradation of dyes. According to the authors, the combination of the advantages of both oxides and the design of a new adsorbent material brings important information in the field of environmental protection regarding removal of toxic azo dyes from wastewater. This is the first report on the adsorptive removal of C.I. Direct Yellow 142, and appears to be valuable information, especially since it may undergo degradation in the aqueous environment into toxic and mutagenic aromatic amines.

\section{Material and methods}

\section{Characteristics of adsorbent and adsorbate}

The mixed $\mathrm{SiO}_{2}-\mathrm{TiO}_{2}$ oxide (consisting of 80 wt. $\% \mathrm{SiO}_{2}$ and $20 \mathrm{wt} . \% \mathrm{TiO}_{2}$; ST20) was synthesized by the pyrogenic method (silicon and titanium tetrachlorides co-burning in a hydrogen-oxygen flame at $1100-1400^{\circ} \mathrm{C}$ ) in the pilot plant at the Institute of Surface Chemistry (Kalush, Ukraine). During the synthesis there were formed $\equiv \mathrm{Ti}-\mathrm{O}-\mathrm{Ti}$ and $\equiv$ Si-O-Si bonds, however, the $\equiv$ Ti-O-Si bonds are also present on the ST20 surface. The detailed characteristics of ST20 mixed oxide can be found in the papers by Gun'ko et al. [12-14] and are presented in fig. 1.

The disazo dye C.I. Direct Yellow 142 (DY142) was used as the adsorbate. It is widely applied in the textile industry during dyeing operations of cellulosic fibers like cotton, flax, viscose rayon, acetate and jute as well as leather and plastic. It was purchased from Boruta-Zachem (Poland). Figure 1 presents its structure.

Surface active agents of the laboratory grade such as sodium dodecyl sulphate (SDS), hexadecyltrimethylammonium bromide (CTAB) and 4-(1,1,3,3-tetramethylbutyl)phenyl-polyethylene glycol (Triton X-100) as well as sodium sulphate and carbonate were purchased from Sigma-Aldrich (Germany) and POCh (Poland), respectively.

\section{Isotherm and kinetic studies}

The batch method was applied in order to determine the equilibrium and kinetic parameters at room temperature. $0.02 \mathrm{~g}$ of ST20 was mixed (speed $180 \mathrm{cpm}, 8$ amplitude) with $20 \mathrm{~mL}$ of DY142 solution of specified concentration from 5 to $240 \mathrm{~min}$ (kinetic studies) or $24 \mathrm{~h}$ (isotherm studies) using a laboratory shaker (Elpin+, model $358 \mathrm{~S}$, Poland). The dye concentration after sorption was determined spectrophotometrically (Cary 60 spectrophotometer, Agilent, USA) at the maximum absorbance wavelength.

The relation between the amount of DY142 adsorbed per gram of ST20 $\left(q_{e}\right)$ in the equilibrium state and the dye content remaining in the solution was determined using the three popular isotherm models:

- Langmuir [15],

$$
\frac{C_{e}}{q_{e}}=\frac{1}{Q_{0} b}+\frac{C_{e}}{Q_{0}}
$$

- Freundlich [16],

$$
\log q_{e}=\log k_{F}+\frac{1}{n} \log C_{e}
$$

- Tempkin [17],

$$
q_{e}=\left(\frac{R T}{b_{T}}\right) \ln A+\left(\frac{R T}{b_{T}}\right) \ln C_{e},
$$

where $q_{e}(\mathrm{mg} / \mathrm{g})$ is the amount of DY142 adsorbed per unit mass of ST20, $C_{e}(\mathrm{mg} / \mathrm{L})$ is the equilibrium concentration of solution, $Q_{0}(\mathrm{mg} / \mathrm{g})$ is the monolayer adsorption capacity, $b(\mathrm{~L} / \mathrm{mg})$ is the Langmuir constant (related to the free energy of adsorption), $k_{F}(\mathrm{mg} / \mathrm{g})$ and $1 / n$ are the Freundlich constants connected with the adsorption capacity of 

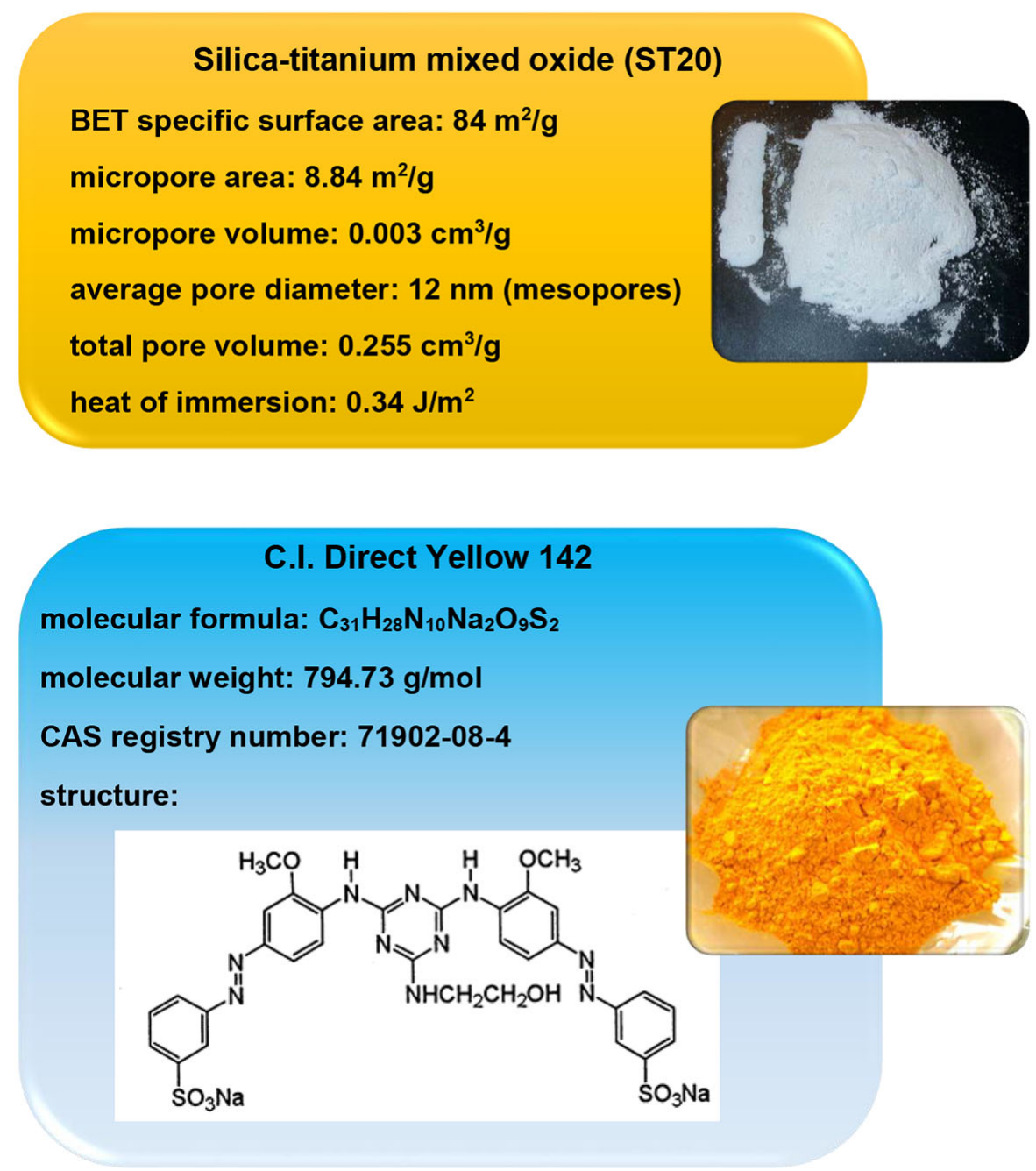

Fig. 1. Adsorbent (ST20) and adsorbate (DY142) characteristics.

adsorbent and the surface heterogeneity, respectively, $R(8.314 \mathrm{~J} / \mathrm{mol} \mathrm{K})$ is the gas constant, $T(\mathrm{~K})$ is the temperature, $A(\mathrm{~L} / \mathrm{g})$ and $b_{T}(\mathrm{~J} / \mathrm{mol})$ are the Tempkin constants.

The adsorption parameters were calculated from the slopes and intercepts of the following plots: $C_{e} / q_{e}$ versus $C_{e}$, $\log q_{e}$ versus $\log C_{e}$ and $q_{e}$ versus $\ln C_{e}$.

The adsorption rate of DY142 on ST20 mixed oxide as a function of time $(t)$ was investigated in the solution of the initial dye concentration $20 \mathrm{mg} / \mathrm{L}$ and analyzed using the following models:

- the pseudo-first order (PFO) [18],

$$
\log \left(q_{e}-q_{t}\right)=\log \left(q_{e}\right)-\frac{k_{1}}{2.303} t
$$

- the pseudo-second order (PSO) [19],

$$
\frac{t}{q_{t}}=\frac{1}{k_{2} q_{e}^{2}}+\frac{1}{q_{e}} t
$$

- the intraparticle diffusion (IPD) [20],

$$
q_{t}=k_{i d} t^{0.5}+C_{i}
$$

where $q_{e}$ and $q_{t}(\mathrm{mg} / \mathrm{g})$ are the amounts of AY219 adsorbed by ST20 at equilibrium and time $t$, respectively, $k_{1}$ $(1 / \mathrm{min})$ is the rate constant of the pseudo-first-order kinetic model, $k_{2}(\mathrm{~g} / \mathrm{mg} \mathrm{min})$ is the rate constant of the pseudosecond-order kinetic model, $k_{i}\left(\mathrm{mg} / \mathrm{g} \mathrm{min}^{0.5}\right)$ is the intraparticle diffusion rate constant, $C_{i}$ is the intercept.

The kinetic parameters were calculated from the slopes and intercepts of the following plots: $\log \left(q_{e^{-}} q_{t}\right)$ versus $t$ $(\mathrm{PFO}), t / q_{t}$ versus $t(\mathrm{PSO})$ and $q_{t}$ versus $t^{0.5}(\mathrm{IPD})$. 
Table 1. Equilibrium isotherm parameters for DY142 adsorption on ST20 mixed oxide.

\begin{tabular}{|c|c|c|c|c|c|c|c|c|}
\hline \multicolumn{3}{|c|}{ Langmuir parameters } & \multicolumn{3}{c|}{ Freundlich parameters } & \multicolumn{3}{c|}{ Tempkin parameters } \\
\hline$r^{2}$ & $\begin{array}{c}Q_{0} \\
(\mathrm{mg} / \mathrm{g})\end{array}$ & $\begin{array}{c}b \\
(\mathrm{~L} / \mathrm{mg})\end{array}$ & $r^{2}$ & $\begin{array}{c}k_{F} \\
(\mathrm{mg} / \mathrm{g})\end{array}$ & $n$ & $r^{2}$ & $\begin{array}{c}b_{T} \\
(\mathrm{~J} / \mathrm{mol})\end{array}$ & $\begin{array}{c}A \\
(\mathrm{~L} / \mathrm{g})\end{array}$ \\
\hline 0.991 & 106.5 & 0.073 & 0.853 & 12.68 & 2.23 & 0.969 & 105.9 & 1.12 \\
\hline
\end{tabular}

In order to determine the influence of auxiliaries (i.e. additives) such as anionic, cationic and non-ionic surfactants and salts $\left(\mathrm{Na}_{2} \mathrm{SO}_{4}\right.$ and $\left.\mathrm{Na}_{2} \mathrm{CO}_{3}\right)$ on DY142 adsorption on ST20, the dye solutions of the initial concentration $20 \mathrm{mg} / \mathrm{L}$ were prepared in the presence of $0.1,0.25$ and $0.5 \mathrm{~g} / \mathrm{L}$ of surfactants or $5,10,20,50$ and $75 \mathrm{~g} / \mathrm{L}$ of salts. The phase contact time, ST20 mass and volume of the dye solution were equal to $30 \mathrm{~min}, 0.02 \mathrm{~g}$ and $20 \mathrm{~mL}$, respectively.

\section{Potentiometric titration method}

The potentiometric titration method leading to the determination of the solid surface charge $\left(\sigma_{0}\right)$ as a function of solution $p \mathrm{H}$ and point of zero charge $\left(p \mathrm{H}_{\mathrm{pzc}}\right)$ of the examined oxide adsorbent, is a very useful tool for adsorption mechanism description in various kinds of colloidal systems containing highly dispersed solid particles [21-25].

Potentiometric titrations were performed for the suspensions of ST20 mixed oxide with the following liquid phases: water (reference solution); dye aqueous solutions of the concentrations 10, 20, $30 \mathrm{mg} / \mathrm{L}$; dye aqueous solution (of the concentration $20 \mathrm{mg} / \mathrm{L}$ ) with the surfactants - SDS, CTAB, Triton X-100 (of the concentration 0.1 g/L); dye aqueous solution (of the concentration $20 \mathrm{mg} / \mathrm{L}$ ) with the salt $-\mathrm{Na}_{2} \mathrm{SO}_{4}$ or $\mathrm{Na}_{2} \mathrm{CO}_{3}$ (of the concentration $10 \mathrm{~g} / \mathrm{L}$ ). To prepare the aqueous suspension, $0.2 \mathrm{~g}$ of the solid was introduced to $50 \mathrm{~mL}$ of appropriate solution. The initial $p \mathrm{H}$ of the solution (before the solid addition) was adjusted to the value of about 3.4. The obtained colloidal systems were titrated with $\mathrm{NaOH}$ (of the concentration $0.1 \mathrm{~mol} / \mathrm{L}$ ) in the $p \mathrm{H}$ range $3-11$. The specialized set composed of the following parts: thermostat RE 204 (Lauda), glass and calomel electrode (Backman Instruments), pH-meter PHM 240 (Radiometer), automatic microburette Dosimat 765 (Metrohm) and computer was applied for potentiometric titration experiments. The special "titr_v3" computer program developed by Janusz [26] controlled automatically the measurements and processed the obtained data into the surface charge density $\left(\mu \mathrm{C} / \mathrm{cm}^{2}\right)$ as a function of $p \mathrm{H}$.

The comparison of titration reference curve with that of the suspension (containing mixed oxide) leads not only to the determination of the $p \mathrm{H}_{\mathrm{pzc}}$ value of the examined system (as a point of the intersection of these two curves) and also to the solid surface charge density calculations. There was used the following equation:

$$
\sigma_{0}=\frac{\Delta V c_{b} F}{m S}
$$

where $c_{b}(\mathrm{~mol} / \mathrm{L})$ is the base $(\mathrm{NaOH})$ concentration, $F(\mathrm{C})$ is the Faraday constant, $m(\mathrm{~g})$ is the solid mass in the suspension, $S\left(\mathrm{~m}^{2} / \mathrm{g}\right)$ is the specific surface area of the solid, $\Delta V(\mathrm{~L})$ is the difference in the volume of base which must be added to bring the $p \mathrm{H}$ of suspension and reference solution to the specified value.

\section{Results and discussion}

\section{Isotherms and kinetics}

The assessment of the adsorption equilibrium provides valuable information about the nature of interactions between the adsorbent and the adsorbate as well as affinity [27]. The equilibrium isotherm parameters obtained from the Langmuir, Freundlich and Tempkin adsorption models using the linear regression are listed in table 1.

The values of determination coefficients $\left(r^{2}\right)$ were used in order to evaluate the best fitted model (fig. 2). It can be stated that the Freundlich model $\left(r^{2}=0.853\right)$ did not describe the equilibrium adsorption data of DY142 on ST20 as well as the Langmuir model $\left(r^{2}=0.991\right)$. The dimensionless constant equilibrium parameter $\left(R_{L}\right)$ [28] equals 0.578, which indicates favourable adsorption of DY142 on ST20 $\left(R_{L}\right.$ values, classifies the adsorption process as favourable for $0<R_{L}<1$ and unfavourable for $R_{L}>1$ ). The monolayer adsorption capacity and the Langmuir constant $b$ related to the free energy of adsorption were calculated as $106.5 \mathrm{mg} / \mathrm{g}$ and $0.073 \mathrm{~L} / \mathrm{mg}$, respectively. This indicates that all adsorption sites of the surface of ST20 have the same energy and the DY142 adsorption occurs at specific homogenous sites on the surface of the mixed oxide. The monolayer adsorption capacity of ST20 for DY142 compared with that of other adsorbents based on the literature review is shown in table 2 . 


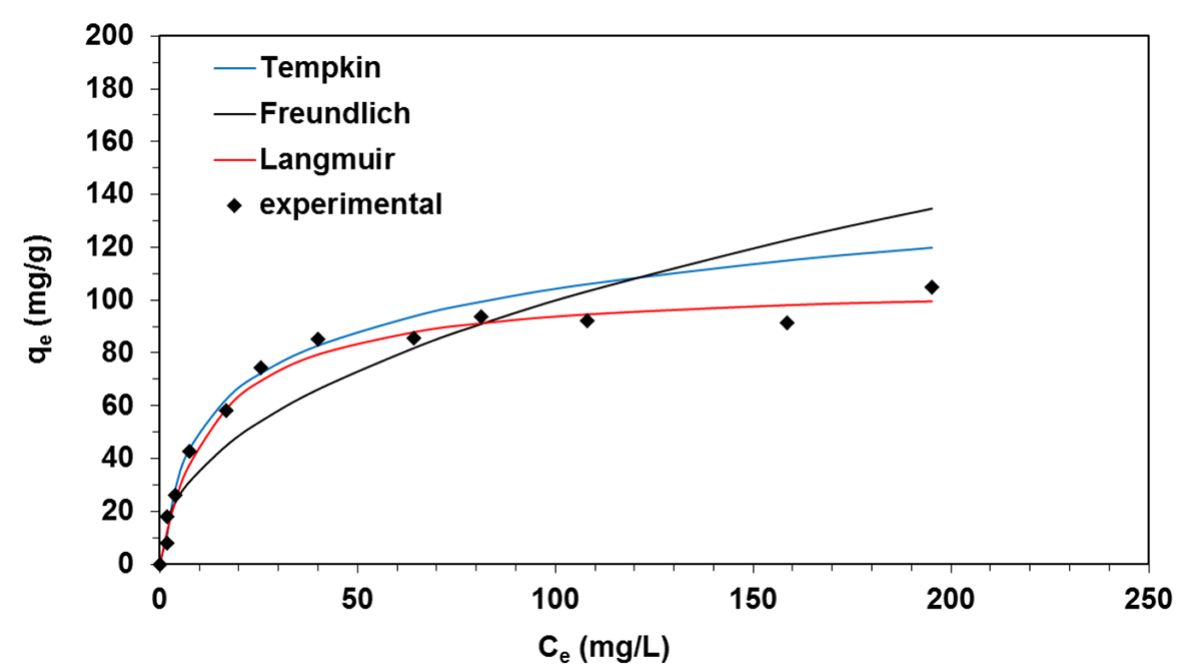

Fig. 2. Fitting of the Langmuir, Freundlich and Tempkin isotherm models to the experimental equilibrium adsorption data of DY142 on ST20.

Table 2. Comparison of maximum adsorption capacities of different oxides for direct dyes.

\begin{tabular}{|l|l|l|l|}
\hline Adsorbent & Adsorbate & $q_{e}(\mathrm{mg} / \mathrm{g})$ & Reference \\
\hline 97 wt. $\% \mathrm{SiO}_{2}-3$ wt. $\% \mathrm{Al}_{2} \mathrm{O}_{3}$ & C.I. Direct Blue 71 & 1.14 & Wawrzkiewicz et al. $(2017)$ \\
\hline 4 wt. $\% \mathrm{SiO}_{2}-96$ wt. $\% \mathrm{Al}_{2} \mathrm{O}_{3}$ & C.I. Direct Blue 71 & 49.2 & Wawrzkiewicz et al. $(2015)$ \\
\hline Apatitic tricalcium phosphate & C.I. Direct Yellow 28 & 67.02 & Boujaady et al. $(2014)$ \\
\hline $\mathrm{Fe}_{3} \mathrm{O}_{4}-$ gelatin & C.I. Direct Yellow 12 & 1250 & Alinejad-Mir et al. $(2018)$ \\
\hline Magnetic $\mathrm{MCM}-41$ & C.I. Direct Blue 6 & 6.3 & Tugce et al. $(2017)$ \\
& C.I. Direct Black 38 & 4.4 & \\
\hline 80 wt. $\% \mathrm{SiO}_{2}-20$ wt. $\% \mathrm{TiO}_{2}$ & C.I. Direct Yellow 142 & 106.5 & This study \\
\hline
\end{tabular}

However, taking into account a relatively large-sized dye molecule of different functional groups it is very difficult to exclude a complex nature of interactions between the dyes anions and ST20. Not only the electrostatic interactions between the positively charged protonated hydroxyl groups of ST20 mixed oxide and the oppositely charged sulfonic group of DY142 occur, but also hydrogen bonding between $\mathrm{N}$ and $\mathrm{O}$ atoms present in the dye structure as well as aromatic rings and $-\mathrm{OH}\left(\right.$ or $-\mathrm{OH}_{2}^{+}$) groups of the mixed oxide and van der Waals forces.

The Tempkin isotherm $\left(r^{2}=0.969\right)$ is related to the indirect interactions between DY142 and ST20 and assumes that heat of adsorption of all dye molecules in the layer will decrease linearly rather than logarithmic with coverage. The constant $A$ related to the maximum binding energy and $b_{T}$ connected with the heat of adsorption were equal to $1.12 \mathrm{~L} / \mathrm{g}$ and $105.9 \mathrm{~J} / \mathrm{mol}$, respectively.

Figure 3 presents the results of the experiments conducted to evaluate the phase contact time necessary to reach dynamic equilibrium in the solution containing $20 \mathrm{mg} / \mathrm{L}$ of DY142.

The amount of DY142 adsorbed by ST20 increased with the increasing phase contact time and after $240 \mathrm{~min} 19 \mathrm{mg} / \mathrm{g}$ of DY142 was taken up (dynamic equilibrium). Dye adsorption proceeds in two stages. The first stage includes initial 30 minutes during which very fast retention of the dye occurs. Another $210 \mathrm{~min}$ (second stage) is a slow process of saturation of adsorption sites. Fast adsorption of DY142 dye and relatively quick attainment of the equilibrium in the system under discussion is very desirable and advantageous for practical applications.

The experimental data were fitted using the pseudo-first-order (PFO), pseudo-second-order (PSO) and intaparticle diffusion (IPD) models as well as assessing and comparing the determination coefficients $\left(r^{2}\right)$ for individual models. The PFO model can not be used for description of the experimental data because of poor linearity $\left(r^{2}=0.560\right)$ of the plot $\log \left(q_{e}-q_{t}\right)$ versus $t$. The sorption capacity calculated from the PFO model $\left(q_{e}=2.54 \mathrm{mg} / \mathrm{g}\right)$ differs significantly from that obtained experimentally $\left(q_{e, \exp }=19 \mathrm{mg} / \mathrm{g}\right)$. Analysing the adsorption capacity obtained from the PSO model $\left(q_{e}=19.64 \mathrm{mg} / \mathrm{g}\right)$, it can be stated that it was consistent with that obtained from the experiment. The determination coefficient was equal to 0.999 . The PSO adsorption rate constant was found to be $0.070 \mathrm{~g} / \mathrm{mg}$ min. The above data suggest that the dye retention on the ST20 mixed oxide can proceed by chemisorption. Applicability of the PSO model for description of acid, reactive, direct and basic dyes on different mixed oxides was confirmed earlier in many papers $[7,8,10,29,30]$. From the plot $q_{t}$ versus $t^{0.5}$ (not shown), the intraparticle diffusion rate constant was calculated 


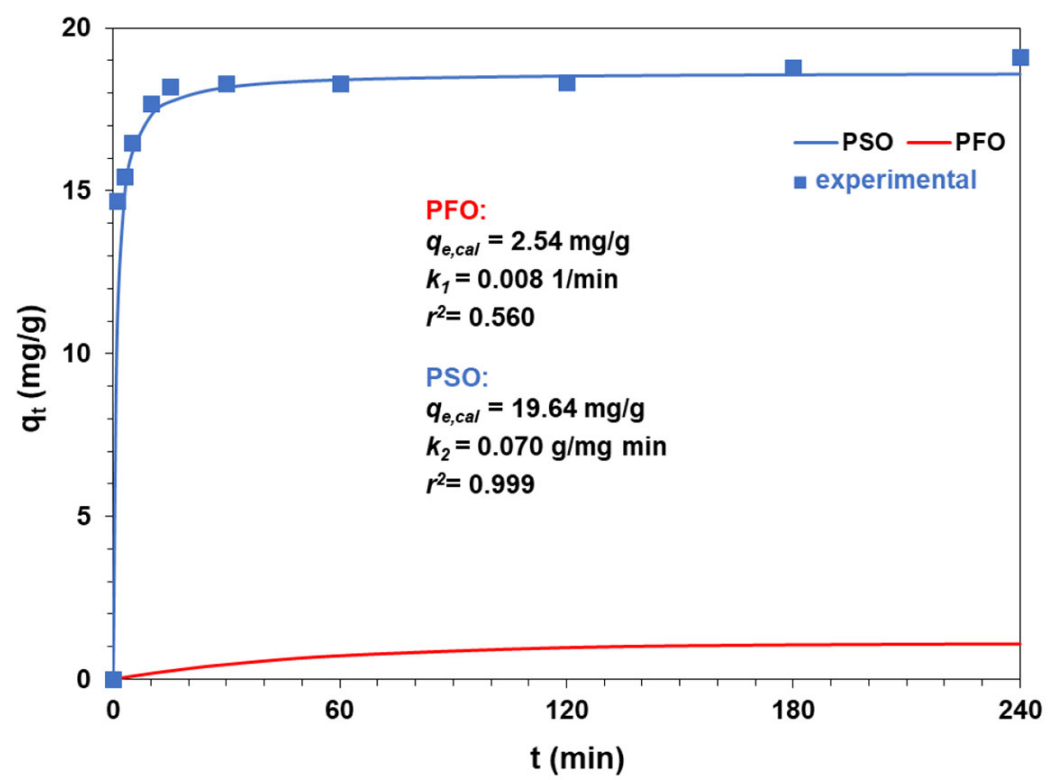

Fig. 3. Kinetic sorption data of DY142 on ST20 as well as fitting of the PFO and PSO models to the experimental data in the system containing $20 \mathrm{mg} / \mathrm{L}$ of the dye.
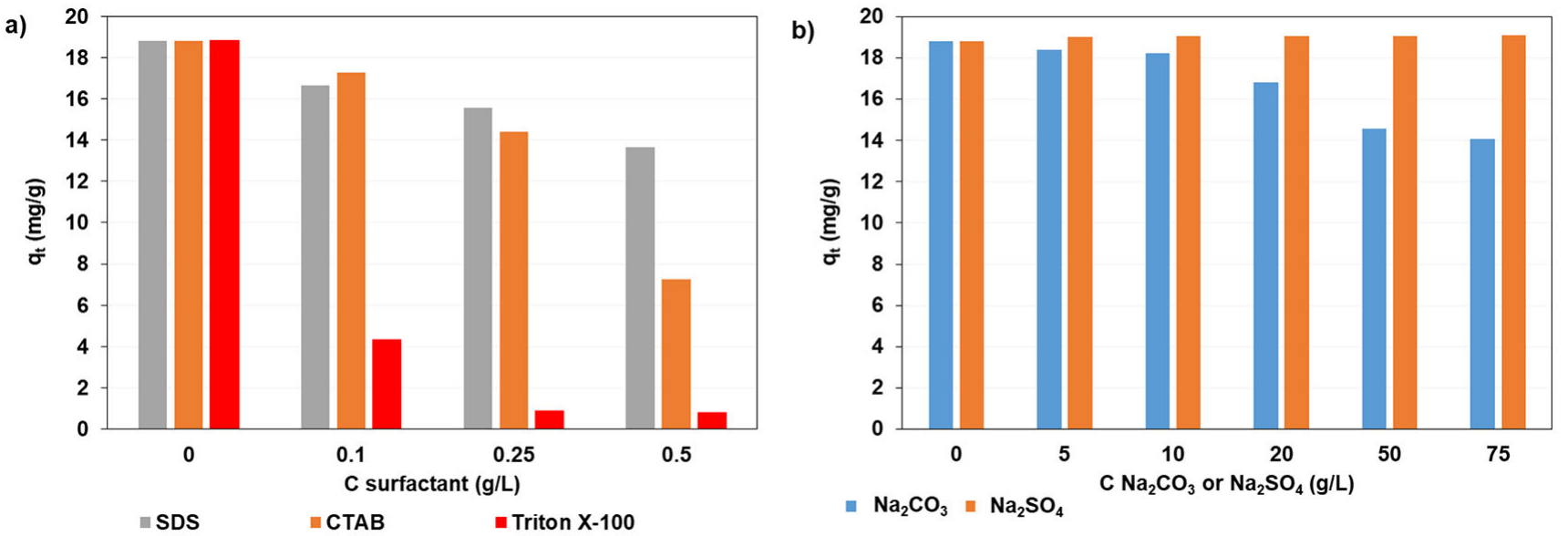

Fig. 4. DY142 uptake by ST20 in the presence of different surfactants and salts.

to be $0.859 \mathrm{mg} / \mathrm{g} \min ^{0.5}\left(r^{2}=0.853\right)$. There can be distinguished two adsorption steps in the plot $q_{t}$ versus $t^{0.5}$ but the regression curve did not pass through the origin. The intercept that is the measure of the boundary layer thickness was found to be 13.4. It shows that the intraparticle diffusion was not the rate-limiting step in DY142 adsorption on ST20 and the external mass transfer occurred simultaneously.

Not only dyeing baths and also effluents originating from the textile industry are rich in different types of additives (commonly called auxiliaries) such as surfactants and electrolytes. It is extremely important to determine their impact on the amount of DY142 adsorbed by ST20 as these substances can increase the dye uptake or decrease its retention. The influence of surfactants (SDS, CTAB and Triton X-100) and salts $\left(\mathrm{Na}_{2} \mathrm{CO}_{3}\right.$ and $\left.\mathrm{Na}_{2} \mathrm{SO}_{4}\right)$ on the DY142 uptake by ST20 from the solutions containing $20 \mathrm{mg} / \mathrm{L}$ of the dye after $30 \mathrm{~min}$ of phase contact time is presented in fig. 4 .

There, a decrease was observed in the DY142 adsorbed amount by ST20 with the increasing amount of surfactants in the system. The most visible impact of the surfactants on the dye retention was observed in the case of non-ionic Triton X-100. However, the decrease in the amount of the dye adsorbed by ST20 can be explained in various ways. In the case of SDS, the observed decrease in the $q_{t}$ values with the increasing amount of surfactant in the range from 0.1 to $0.5 \mathrm{~g} / \mathrm{L}$ can be explained by the competitive sorption of SDS in comparison with the anionic form of the dye. This effect of SDS on the amount of adsorbed dye was found in the case of C.I. Direct Blue 71 [7] and C.I. Reactive Black $5[30]$ adsorption on the mixed silica-alumina oxide SA96 consisting of 4 wt.\% $\mathrm{SiO}_{2}$ and 96 wt.\% $\mathrm{Al}_{2} \mathrm{O}_{3}$. Similar results were described during C.I. Acid Orange 7, C.I. Reactive Black 5 and C.I. Direct Blue 71 adsorption on the aminosilane modified silica [29]. In the case of CTAB, reducing the amount of DY142 dye adsorbed by ST20 can be explained by the electrostatic interactions between the anionic form of the dye and the surfactant endowed with a positive charge. 


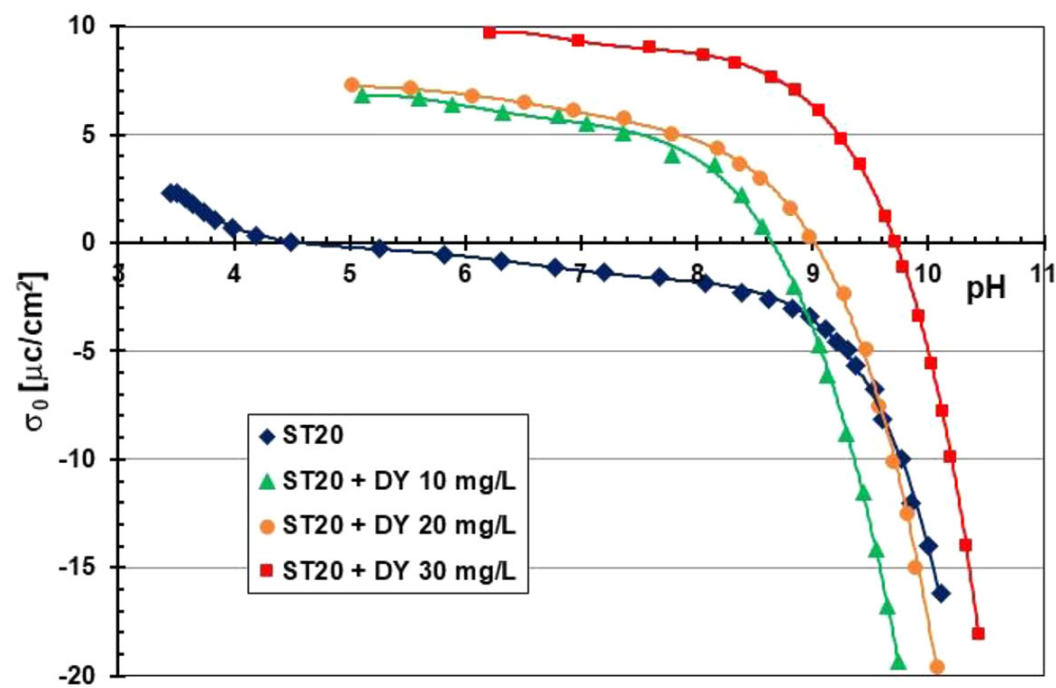

Fig. 5. Surface charge density of ST20 without and in the presence of DY142 with different concentrations.

The most noticeable influence of the surfactant on the amount of adsorbed dye by ST20 was observed in the case of non-ionic Triton X-100. It is supposed that Triton X-100 formed strong complexes with the dye molecules in the solution, consequently not a large number of uncomplexed dye anions can adsorb on the solid surface.

The presence of sodium sulphate does not affect the retention of DY142 dye by ST20 significantly which is extremely important from a practical point of view because this electrolyte is found in dyeing baths in high concentration providing proper conditions for dye binding to the fiber thus reaching the wastewaters in the quantities in which it was introduced to the colouring bath. Increasing the concentration of sodium carbonate in the system in the range from 5 to $75 \mathrm{~g} / \mathrm{L}$ drop of the amount of DY142 adsorbed by ST20 from 18.81 to $14.1 \mathrm{mg} / \mathrm{g}$, respectively was observed.

\section{Electrical double-layer structure of silica-titania/dye solution interface in the presence of surfactant and salt}

The surface charge at the metal oxide-aqueous solution interface is formed in the processes of hydroxylation (-OH groups formation) and next proton connection or disconnection. In the case of applied ST20 mixed oxide on which surface $\equiv \mathrm{TiOTi}, \equiv \mathrm{SiOSi}$ and $\equiv \mathrm{TiOSi}$ groups are present, in the aqueous solution $\equiv \mathrm{TiOTi}-\mathrm{OH}$, $\equiv \mathrm{SiOSi}-\mathrm{OH}$ and $\equiv$ TiOSi-OH groups are formed [31]. Due to the fact that these hydroxyl groups are of amphoteric character, depending on the solution $p \mathrm{H}$ value, these groups can connect proton (positively charged groups formation, i.e. $\equiv \mathrm{TiOTi}^{-\mathrm{OH}} \mathrm{H}_{2}^{+}$) or disconnect proton (negatively charged groups formation, i.e. $\equiv \mathrm{TiOTi}^{-} \mathrm{O}^{-}$). The surface concentration of these charged groups is characteristic of each metal oxide and it determines the magnitude and sign of the solid surface charge density as well as the value of point of zero charge. As can be seen in fig. 5 the $p \mathrm{H}_{\mathrm{pzc}}$ of ST20 mixed oxide (dispersed in water) assumes the value 4.6. Therefore at $p \mathrm{H}$ lower than 4.6 the solid surface is positively charged $\left(\sigma_{0}\right.$ reaches the value $\left.2.4 \mu \mathrm{C} / \mathrm{cm}^{2}\right)$ and at $p \mathrm{H}$ higher than 4.6 it is negatively charged $\left(\sigma_{0}\right.$ reaches the value $\left.-16.2 \mu \mathrm{C} / \mathrm{cm}^{2}\right)$.

The adsorption of anionic C.I. Direct Yellow 142 dye on the ST20 surface causes pronounced increase of the solid surface density in the whole range of the studied $p \mathrm{H}$ and shift of the $p \mathrm{H}_{\mathrm{pzc}}$ point towards the higher $p \mathrm{H}$ values. These effects are more and more visible when the concentration of DY142 increases. The $p \mathrm{H}_{\mathrm{pzc}}$ points assume the following values: 8.62 for the dye concentration $10 \mathrm{mg} / \mathrm{L}, 9$ for $20 \mathrm{mg} / \mathrm{L}$ and 9.7 for $30 \mathrm{mg} / \mathrm{L}$. Similar behaviour is often observed for the adsorbates of anionic character - i.e. simple inorganic anions and organic polyanions [32-34]. Their electrostatic interactions with the hydroxyl groups on the solid surface cause creation of the additional number of positively charged surface groups according to the reaction:

$$
\equiv \mathrm{TiOTi}-\mathrm{OH}+\mathrm{DY}^{-}+\mathrm{H}^{+} \leftrightarrow \equiv \mathrm{TiOTi}_{-} \mathrm{OH}_{2}^{+} \mathrm{DY}^{-}
$$

This leads to the increase of mixed oxide surface charge density. It is obvious that the number of positive groups formed on the solid surface is greater in the case of higher dye concentration and $\sigma_{0}$ assumes higher values (reaching $9.7 \mu \mathrm{C} / \mathrm{cm}^{2}$ for the dye concentration $\left.30 \mathrm{mg} / \mathrm{L}\right)$. The opposite behaviour occurred in the case of anionic polymer adsorption (i.e. poly(acrylic acid)) on the activated carbons surfaces $[35,36]$. In such a case the considerable decrease of the solid surface charge density was observed after the polymer addition. The presence of numerous PAA segments containing negatively charged carboxyl groups in the by-surface layer of the solution was responsible for significant lowering of the $\sigma_{0}$ values. 


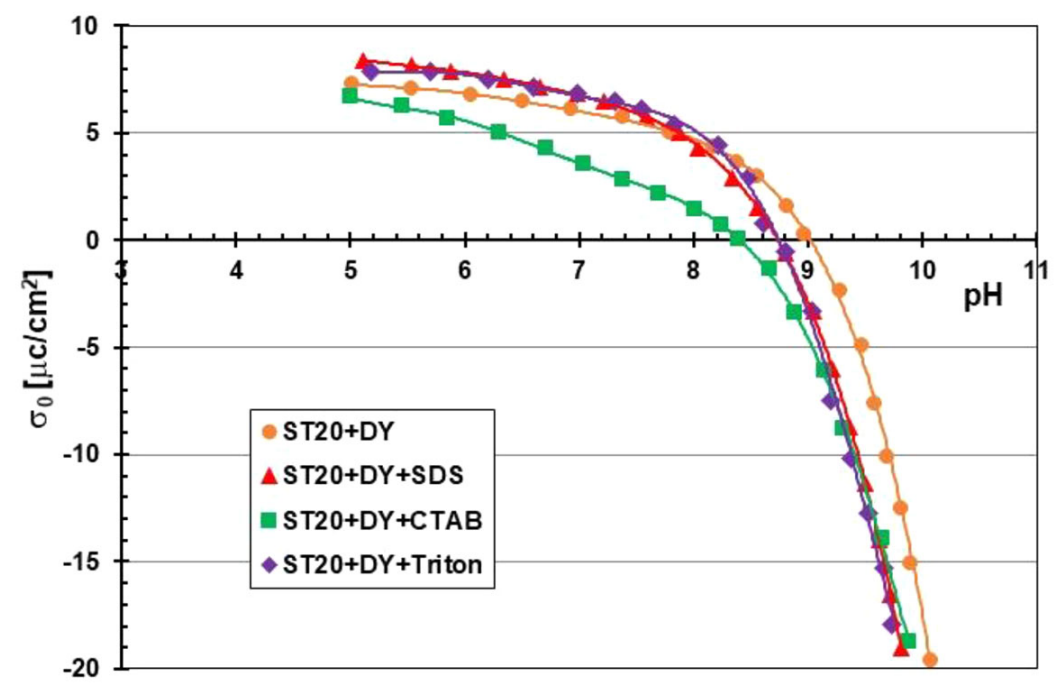

Fig. 6. Surface charge density of ST20 in the presence of DY142 with concentration $20 \mathrm{mg} / \mathrm{L}$ and various surfactants (with concentration $0.1 \mathrm{~g} / \mathrm{L})$.

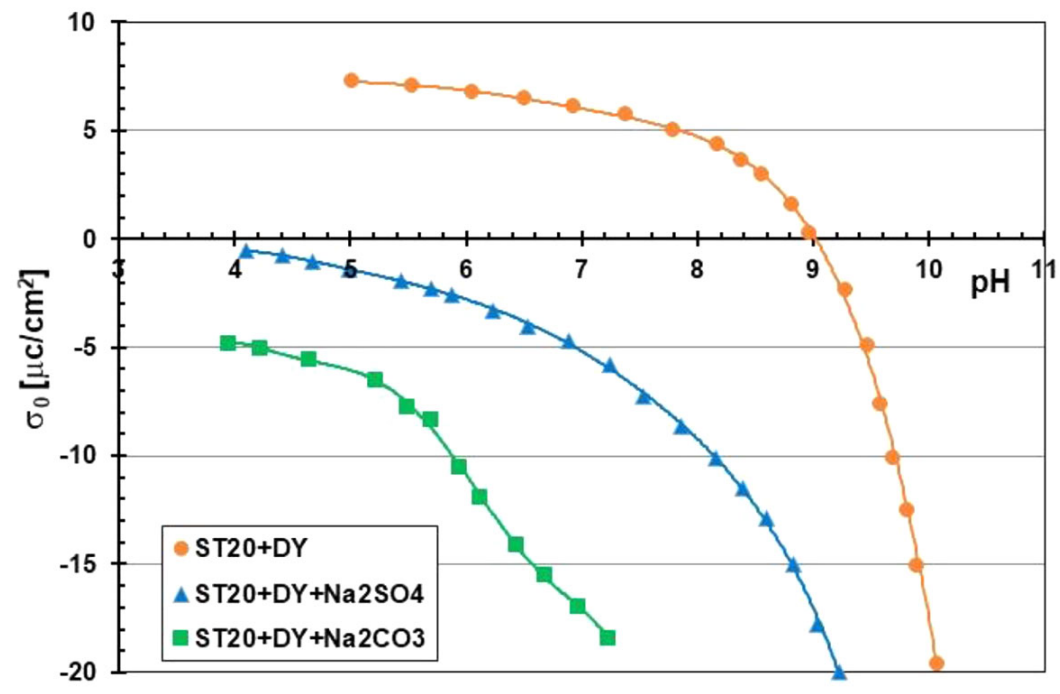

Fig. 7. Surface charge density of ST20 in the presence of DY142 with concentration $20 \mathrm{mg} / \mathrm{L}$ and various salts (with concentration $10 \mathrm{~g} / \mathrm{L})$.

Both the anionic SDS and non-ionic Triton X-100 addition affects minimally the ST20 solid surface charge in the C.I. Direct Yellow 142 presence (fig. 6). The significant decrease of the $\sigma_{0}$ values was observed after the cationic CTAB addition (especially in the $p \mathrm{H}$ range 4.5-8.5).

The competitive adsorption of DY142 and SDS molecules (both of anionic character) has a minimal impact on the solid surface charge density. The formation of complexes between the DY142 and Triton X-100 molecules in solution results in flat adsorption of uncomplexed dye molecules. As a result, the total surface charge density changes insignificantly in comparison to the system without the non-ionic surfactant, in which dye adsorbed molecules form more developed (thicker) surface layers.

In the case of the dye-CTAB/ST20 system a remarkable decrease of the solid surface charge density was observed. The formed dye-cationic surfactant complexes and single CTAB molecules can interact with the solid hydroxyl groups, providing negative charges creation on the mixed oxide surface ( $\sigma_{0}$ decrease).

The salt addition (both $\mathrm{Na}_{2} \mathrm{SO}_{4}$ and $\mathrm{Na}_{2} \mathrm{CO}_{3}$ ) to the dye solution causes a considerable decrease of the ST20 surface charge density in the whole range of the studied $p \mathrm{H}$ values (fig. 7). The adsorption results indicate that the presence of salt (of the concentration $10 \mathrm{~g} / \mathrm{L}$ ) practically does not influence the adsorbed amounts of DY142. Nevertheless, inorganic ions of dissociated salt ions (especially $\mathrm{Na}^{+}$) can locate in the surface layer between the adsorbed dye molecules, which are considerably smaller than the DY142 molecules. Small inorganic ions can penetrate easily the adsorption layer of C.I. Direct Yellow 142, significantly decreasing the solid surface charge. 


\section{Conclusions}

Mixed silica-titanium oxide ( $80 \mathrm{wt} . \% \mathrm{SiO}_{2}$ and $20 \mathrm{wt} . \% \mathrm{TiO}_{2} ; \mathrm{ST} 20$ ) was synthesized by the pyrogenic method and applied for the hazardous azo dye (C.I. Direct Yellow 142; DY142) removal from the aqueous solutions. Some of the important findings include the following:

- The specific surface area of the mixed oxide was found to be $84 \mathrm{~m}^{2} / \mathrm{g}$, the micropore area was $8.84 \mathrm{~m}^{2} / \mathrm{g}$, the micropore volume was $0.003 \mathrm{~cm}^{3} / \mathrm{g}$, the average pore diameter was $12 \mathrm{~nm}$ (mesopores) and the total pore volume was $0.255 \mathrm{~cm}^{3} / \mathrm{g}$.

- The adsorption capacity of ST20 towards DY142 equals $106.5 \mathrm{mg} / \mathrm{g}$, the best fitting of experimental equilibrium data was obtained using the Langmuir isotherm model.

- The kinetic experiments revealed that in the system containing $20 \mathrm{mg} / \mathrm{L}$ of dye, the phase contact time necessary to reach dynamic equilibrium was $240 \mathrm{~min}$; it was found that the amount of DY142 retained by ST20 was equal to $19 \mathrm{mg} / \mathrm{g}$; the good fit of the pseudo-second-order model $\left(r^{2}=0.999\right)$ to the experimental data confirmed that chemisorption is the rate controlling step of adsorption,

- A significant drop in the amount of DY142 uptake by ST20 was noticed in the presence of such surfactants as SDS, CTAB and Triton X-100.

- The presence of $\mathrm{Na}_{2} \mathrm{SO}_{4}$ in the range of $5-75 \mathrm{~g} / \mathrm{L}$ did not influence the dye retention by $\mathrm{ST}_{20}$ whereas $\mathrm{Na}_{2} \mathrm{CO}_{3}$ caused the drop of $q_{t}$ values.

- The anionic dye adsorption causes a significant increase of the solid surface charge density; it is connected with the formation of positively charged groups on the ST20 surface caused by the interactions with the negatively charged DY142 molecules.

- The presence of the cationic surfactant results in the greatest changes in the $\sigma_{0}$ values of ST20/dye system - the solid surface charge decrease was observed; the addition of anionic SDS and non-ionic Triton X-100 affects the surface properties of the examined systems to a small extent. On the other hand, the presence of the salt results in a significant decrease of the mixed oxide surface charge.

The research leading to these results has received funding from the People Programme (Marie Curie Actions) of the European Union's Seventh Framework Programme FP7/2007-2013/under REA grant agreement n PIRSES-GA-2013-612484.

Publisher's Note The EPJ Publishers remain neutral with regard to jurisdictional claims in published maps and institutional affiliations.

Open Access This is an open access article distributed under the terms of the Creative Commons Attribution License (http://creativecommons.org/licenses/by/4.0), which permits unrestricted use, distribution, and reproduction in any medium, provided the original work is properly cited.

\section{References}

1. J. Mielicki, Outline of chemical treatment of textile products (Scientific and Technical Publisher, Warsaw, 1991).

2. X.-Ch. Jin, G.-Q. Liu, Z.-H. Xu, W.-J. Tao, Appl. Microbiol. Biotechnol. 74, 239 (2007).

3. C. Hessel, C. Allegre, M. Maisseu, F. Charbit, P. Moulin, J. Environ. Manag. 83, 171 (2007).

4. S. Wijannarong, S. Aroonsrimorakot, P. Thavipoke, A. Kumsopa, S. Sangjan, Biol. Environ. Eng. Sci. 5, 279 (2013).

5. M.T. Yagub, T. Kanti Sen, S. Afroze, H.M. Ang, Adv. Colloid Interface Sci. 209, 172 (2014).

6. S. Rasalingam, R. Peng, R.T. Koodali, J. Environ. Manag. 128, 530 (2013).

7. M. Wawrzkiewicz, M. Wiśniewska, V.M. Gun'ko, V.I. Zarko, Powder Technol. 278, 306 (2015).

8. M. Wawrzkiewicz, M. Wiśniewska, A. Wołowicz, V.M. Gun'ko, V.I. Zarko, Micropor. Mesopor. Mater. 250, 128 (2017).

9. U. Pal, A. Sandoval, S.I.U. Madrid, G. Corro, V. Sharma, P. Mohanty, Chemosphere 163, 142 (2016).

10. F. Ciesielczyk, P. Bartczak, J. Zdarta, T. Jesionowski, J. Environ. Manag. 204, 123 (2017).

11. M. Tanzifi, M.T. Yaraki, A.D. Kiadehi, S.H. Hosseini, M. Olazar, A.K. Bharti, S. Agarwal, V.K. Gupta, A. Kazemi, J. Colloid Interface Sci. 510, 246 (2018).

12. V.M. Gun'ko, J.P. Blitz, K. Gude, V.I. Zarko, E.V. Goncharuk, Y.M. Nychiporuk, R. Leboda, J. Skubiszewska-Zieba, V.D. Osovskii, Y.G. Ptushinskii, O.A. Mishchuk, S.V. Pakhovchishin, P.P. Gorbik, J. Colloid Interface Sci. 314, 119 (2007).

13. V.M. Gun'ko, Y.M. Nychiporuk, V.I. Zarko, E.V. Goncharuk, O.A. Mishchuk, R. Leboda, J. Skubiszewska-Zięba, E. Skwarek, W. Janusz, G.R. Yurchenko, V.D. Osovskii, Y.G. Ptushinskii, V.V. Turov, P.P. Gorbik, J.P. Blitz, K. Gude, Appl. Surf. Sci. 253, 3215 (2007).

14. V.M. Gun'ko, E.M. Pakhlov, J. Skubiszewska-Zieba, J.P. Blitz, Vib. Spectrosc. 88, 56 (2017).

15. I. Langmuir, J. Am. Chem. Soc. 40, 1361 (1918).

16. H.M.F. Freundlich, J. Phys. Chem. 57, 385 (1906). 
17. M.I. Tempkin, V. Pyzhev, Acta Phys. Chim. USSR 12, 327 (1940).

18. S. Lagergren, Kungliga Svenska Vetensk. Handl. 24, 1 (1898).

19. Y.S. Ho, G. McKay, Process Biochem. 34, 451 (1999).

20. W.J. Weber, J.C. Morris, J. Sanit. Eng. Div. ASCE 18, 31 (1963).

21. S. Chibowski, M. Krupa, J. Disp. Sci. Tech. 21, 761 (2000).

22. S. Chibowski, M. Wiśniewska, T. Urban, Adsorption 16, 321 (2010).

23. M. Wiśniewska, K. Terpiłowski, S. Chibowski, T. Urban, V.I. Zarko, V.M. Gun'ko, Powder Technol. 233, 190 (2013).

24. M. Wiśniewska, P. Nowicki, V.M. Bogatyrov, A. Nosal-Wiercińska, R. Pietrzak, Colloids Surf. A 492, 12 (2016).

25. E. Skwarek, A. Gładysz-Płaska, Y. Bolbukh, Nanoscale Res. Lett. 12, 278 (2017).

26. W. Janusz, Polish J. Chem. 68, 1871 (1994).

27. K.Y. Foo, B.H. Hameed, Chem. Eng. J. 156, 2 (2010).

28. T.N. Webber, R.K. Chakravarti, J. Am. Inst. Chem. Eng. 20, 228 (1974).

29. M. Wawrzkiewicz, M. Nowacka, Ł. Klapiszewski, Z. Hubicki, Open Chem. 13, 82 (2015).

30. M. Wawrzkiewicz, M. Wiśniewska, V.M. Gun'ko, Adsorption Sci. Technol. 35, 448 (2017).

31. V.M. Gun'ko, V.I. Zarko, I.F. Mironyuk, E.V. Goncharuk, N.V. Guzenko, M.V. Borysenko, P.P. Gorbik, O.A. Mishchuk, W. Janusz, R. Leboda, J. Skubiszewska-Zięba, W. Grzegorczyk, M. Matysek, S. Chibowski, Colloids Surf. A 240, 9 (2004).

32. E. Skwarek, M. Matysek-Nawrocka, W. Janusz, V.I. Zarko, V.M. Gun'ko, Physicochem. Prob. Min. Process. 42, 153 (2008).

33. I. Ostolska, M. Wiśniewska, A. Nosal-Wiercińska, A. Szabelska, B. Gołębiowska, Colloids Surf. A 488, 138 (2016).

34. M. Wiśniewska, Colloid Polym. Sci. 289, 341 (2011).

35. M. Wiśniewska, P. Nowicki, A. Nosal-Wiercińska, R. Pietrzak, K. Szewczuk-Karpisz, I. Ostolska, D. Sternik, Colloids Surf. A 514, 137 (2017).

36. M. Wiśniewska, A. Nosal-Wiercińska, I. Ostolska, D. Sternik, P. Nowicki, R. Pietrzak, A. Bazan-Wozniak, O. Goncharuk, Nanoscale Res. Lett. 12, 2 (2017). 